УДК 581.134.6:582.572.8(571.14)

\title{
БИОЛОГИЧЕСКИ АКТИВНЫЕ ВЕЩЕСТВА ВЕГЕТАТИВНЫХ ОРГАНОВ HOSTA LANCIFOLIA ENGL. (HOSTACEAE)
}

\author{
(C) Л.Л. Седельникова*, Т.А. Кукушкина \\ Центральный сибирский ботанический сад СО РАН, ул. Золотодолинская, \\ 101, Новосибирск, 630090 (Россия), e-mail: lusedelnikova@yandex.ru
}

\begin{abstract}
Определен количественный состав запасных и биологически активных веществ вегетативных органов Hosta lancifolia. Впервые в условиях лесостепной зоны Западной Сибири установлено содержание сахаров, крахмала, сапонинов, аскорбиновой кислоты, пектинов, протопектинов, катехинов в корневищах и листьях данного вида в течение нескольких вегетационных периодов. Установлено, что содержание биологически активных веществ вегетативных органов $H$. lancifolia зависит от индивидуального и сезонного развития вида. Аскорбиновой кислоты в надземных органах больше в 3-7 раз, чем подземных; сахаров - в 2-10, катехинов - в 1,2-2, пектинов - в 2-5, протопектинов в 2 раза. Количество сырого сапонина увеличивается осенью в 8-9 раз. Содержание крахмала в подземных органах изменяется в течение сезонного развития, к осени оно увеличивается на $20-40 \%$.

Ключевые слова: сахар, крахмал, сапонины, аскорбиновая кислота, флавонолы, пектины, протопектины, катехины, лист, корневище, хоста ланцетолистная, Западная Сибирь.
\end{abstract}

\section{Введение}

Исследование адаптационных возможностей растений при интродукции в лесостепную зону Западной Сибири особенно актуально и связано с биохимическими процессами, в частности с накоплением биологически активных веществ в вегетативных органах растений. Среди них представители короткокорневищных геофитов из рода Hosta Tratt.

Род Hosta Tratt. (Funkia Spreng.), семейство хостовых - Hostaceae Tratt., в природе распространен в теплоумеренной зоне Восточной Азии (Китай, Япония, Корея). Только два вида: хоста ланцетолистная Hosta lancifolia Engl. и хоста прямолистная - H. rectifolia Nakai произрастают в муссонном климате юга Приморья, Сахалина, Курильских островов $[1,2]$. Хосты широко используются в декоративном цветоводстве. Компонентный состав вегетативных органов у хост практически не изучен. Известно, что представители этого рода содержат флавоноиды, из группы флавонолов - кемпферол и кверцетин [3-5]. Сведения о содержании метаболитов основных групп веществ и динамики их накопления в надземных и подземных органах на видовом уровне отсутствуют. Это послужило основанием для выполнения настоящей работы.

Цель исследования - сравнительная характеристика содержания биологически активных веществ в вегетативных органах Hosta lancifolia в условиях лесостепной зоны Западной Сибири.

\section{Экспериментальная часть}

Работа проведена в Центральном сибирском ботаническом саду (ЦСБС) СО РАН в 2010-2012 гг. Исследуемый вид - H. lancifolia - хоста ланцетолистная, длительно вегетирующий летнецветущий декоративнолиственный, короткокорневищный поликарпик [6]. Материал получен однолетними вегетативными особями в 2005 г. из отдела декоративных растений Дальневосточного ботанического сада (Владивосток,

Седельникова Людмила Леонидовна - доктор биологических наук, старший научный сотрудник, e-mail: lusedelnikova@yandex.ru

Кукушкина Татьяна Абдулхаиловна - старший научный сотрудник куратор - к.б.н. Н.А. Павлюк). Опытные растения выращивали на интродукционном участке, расположенном в юго-восточном районе Приобского округа лесостепной климатической провинции Новосибирска. Сырье собирали у растений шести-

\footnotetext{
* Автор, с которым следует вести переписку.
} 
восьмилетнего возрастного состояния. По гидротермическим показателям тепла и запасам влаги в годы сбора сырья 2010 г. был теплый, умеренно увлажненный; 2011 г. - слабозасушливый, с ранней теплой весной; 2012 г. - теплый, засушливый.

Для определения количественного содержания веществ (пектины, протопектины, катехины, сахара, крахмал, флавонолы, сапонины и аскорбиновая кислота) использовали свежесобранное сырье, листья и корневища согласно фенофазам развития. Пробы для анализа (навески 5-10 г) брали на аналитических весах с точностью до четвертого знака в течение вегетационного периода: III декада мая (массовое отрастание), III декада июля (массовое цветение), III декада сентября (плодоношение) до наступления в условиях Новосибирска устойчивых морозов. Пектиновые вещества определяли карбазольным методом, основанным на появлении специфического фиолетово-розового окрашивания при взаимодействии уроновых кислот с карбазолом в сернокислой среде, освобождаясь прежде от сахаров и липофильных веществ 3кратным экстрагированием на кипящей водяной бане навесок 80-82\% этиловым спиртом в течение 30 мин. Плотность окрашенных растворов замеряли на ФЭК-56М при длине волны 535 нм в кювете с рабочей длиной 5 мм. Количественное содержание пектиновых веществ определяли по калибровочной кривой, построенной по галактуроновой кислоте [7]. Для определения количественного содержания сахаров использовали метод А.С. Швецова и Э.Х. Лукьяненко, основанный на восстановлении феррицианида калия редуцирующими сахарами в щелочной среде до ферроцианида. Количество сахаров определяли по калибровочному графику, построенному по глюкозе [7]. Катехины определяли спектрофотометрическим методом, основанном на определении оптической плотности раствора взаимодействия катехинов с 1\% раствором ванилина в концентрированной соляной кислоте. Удельный показатель рассчитан по ( \pm )-катехину «Sigma» [8]. Плотность раствора замеряли при длине волны 504 нм. Количественное определение флавонолов проводили спектрофотометрически по методу В.В. Беликова и М.С. Шрайдер [9], в котором использована реакция комплексообразования флавонолов с хлоридом алюминия. Расчет проведен по удельному показателю стандартного образца рутина. Содержание крахмала определяли методом кислотного гидролиза [10]. Метод количественного определения аскорбиновой кислоты основан на ее способности восстанавливать 2,6-дихлорфенилиндофенол. Тщательно измельченную аналитическую навеску (3-5 г) экстрагировали (растирая в ступке) 5 мин 1\% раствором соляной кислоты, добавляя 1\% раствор щавелевой кислоты, которая улучшает стойкость аскорбиновой кислоты в экстракте [11]. Присутствие сапонинов было установлено в результате качественных реакций [12]: 1) пенообразование, равное по объему и стойкости при встряхивании экстракта с кислым и щелочным раствором; 2) тритерпеновые сапонины осаждаются средним ацетоном свинца из водных растворов сапонинов, а стероидные - основным. При определении количественного содержания сапонинов измельченные образцы экстрагировали хлороформом в аппарате Сокслета для извлечения липидов, смол и др. Образцы высушивали и экстрагировали на водяной бане при $70{ }^{\circ} \mathrm{C}$ в течение 30 мин последовательно 50, 60 и 96\% этанолом. Объединенный экстракт упаривали до отсутствия запаха спирта и добавляли семикратный объем ацетона. Осадок через 18 ч отфильтровывали, высушивали при $70{ }^{\circ} \mathrm{C}$ и взвешивали [13]. Все биохимические показатели, кроме аскорбиновой кислоты, рассчитаны на массу абсолютно сухого сырья. Для анализа использовали надземные органы (листья) и подземные (корневища). Определения проводили в трехкратной повторности, среднеарифметические значения биохимических показателей (M) представлены в таблицах 1 и 2. Ошибка \pm m соответствовала допустимым значениям достоверности и была крайне мала $(0,001-0,003)$.

Таблица 1. Средние (М) биохимические показатели веществ (\% на абсолютно сухой вес) в подземных органах Hosta lancifolia в условиях Новосибирска за 2010-2012 гг.

\begin{tabular}{c|c|c|c|c|c|c|c}
\hline Год & Месяц & $\begin{array}{c}\text { Аскорбиновая } \\
\text { кислота }\end{array}$ & Сахара & Пектины & Протопектины & Катехины & Сапонины \\
\hline \multirow{2}{*}{2010} & май & 8,39 & 3,70 & 1,71 & 3,59 & 0,03 & 9,21 \\
& июль & 12,80 & 5,93 & 1,72 & 6,52 & 0,07 & 13,71 \\
& сентябрь & 6,59 & 2,38 & 2,54 & 4,25 & 0,04 & 14,73 \\
\hline \multirow{3}{*}{2011} & май & 7,76 & 3,49 & 2,55 & 7,68 & 0,02 & 7,18 \\
& июль & 11,83 & 1,81 & 0,74 & 3,81 & 0,05 & 24,81 \\
& сентябрь & 5,53 & 7,34 & 1,32 & 5,24 & 0,10 & 22,92 \\
\hline \multirow{2}{*}{2012} & май & 13,32 & 4,61 & 0,69 & 5,34 & 0,05 & 18,30 \\
& июль & 21,26 & 4,89 & 2,08 & 4,69 & 0,31 & 11,20 \\
& сентябрь & 10,47 & 4,91 & 1,86 & 4,16 & 0,03 & 4,07 \\
\hline
\end{tabular}

Примечание: *содержание приводится в мг\%. 
Таблица 2. Средние (М) биохимические показатели веществ (\% на абсолютно сухой вес) в надземных органах Hosta lancifolia в условиях Новосибирска за 2010-2012 гг.

\begin{tabular}{c|c|c|c|c|c|c|c}
\hline Год & Месяц & $\begin{array}{c}\text { Аскорбиновая } \\
\text { кислота }\end{array}$ & Сахара & Пектины & Протопектины & Катехины & Сапонины \\
\hline \multirow{2}{*}{2010} & май & 39,78 & 18,62 & 1,72 & 5,09 & 0,15 & 13,71 \\
& июль & 50,80 & 9,10 & 0,78 & 5,44 & 0,69 & 2,49 \\
& сентябрь & 42,37 & 20,98 & 0,43 & 4,29 & 0,11 & 2,80 \\
\hline \multirow{3}{*}{2011} & май & 38,67 & 8,86 & 1,45 & 5,34 & 0,08 & 13,82 \\
& июль & 54,22 & 7,85 & 0,98 & 4,42 & 0,12 & 8,39 \\
& сентябрь & 121,00 & 7,34 & 1,32 & 5,24 & 0,10 & 22,92 \\
\hline \multirow{2}{*}{2012} & май & 177,40 & 18,02 & 5,65 & 7,67 & 0,10 & 12,40 \\
& июль & 78,11 & 4,89 & 0,97 & 6,33 & 0,41 & 10,93 \\
& сентябрь & 41,61 & 13,41 & 1,24 & 5,27 & 0,09 & 25,71 \\
\hline
\end{tabular}

Примечание: *содержание приводится в мг\%.

В результате проведенного исследования метаболитов основных групп веществ в надземных и подземных органах H. lancifolia нами обнаружено шесть общих компонентов: аскорбиновая кислота, сахара, пектины, протопектины, катехины, сапонины. В корневищах отмечено наличие крахмала, а в листьях флавонолов. Установлено, что их содержание в органах H. lancifolia изменяется как в течение одного вегетационного периода, так и по годам исследования и зависит от специфики выполняемых функций данных органов. Для сравнения рассмотрим динамику их распределения по органам.

Подземные органы. По содержанию запасных веществ в корневищах H. lancifolia обнаружены сахара и крахмал. Накопление сахаров в 2010 г. было наибольшим (5,93\%) в период массового цветения и в 2 раза меньше к предзимью (сентябрь). В 2011 г., наоборот, их содержание достигало максимума в сентябре (7,34\%), в мае было в 2 раза меньше, а в июле составляло минимум (1,81\%). Таким образом, с весны в период роста и развития вегетативных и генеративных органов наблюдали понижение содержания сахара в подземных органах в 2 раза, а к осени интенсивное накопление в зимующих корневищах. В 2012 г. содержание сахаров было стабильным (4,61-4,91\%) в течение всего вегетационного периода (табл. 1).

Накопление крахмала отмечено к предзимью в теплый умеренно-увлажненный вегетационный период 2010 г. на 7,1\% по сравнению с маем. В слабозасушливый 2011 г. в мае, наоборот, его количество сократилось на $5,7 \%$ и составляло $24,9 \%$. К июлю оно возрастало на $15 \%$, а к сентябрю уменьшалось на $8,7 \%$. В теплый засушливый 2012 г. самое высокое содержание крахмала отмечено в июне - 37,07\%, с понижением на 4-6\% к предзимью (рис. 1).

Отмечено, что во все годы наблюдений в подземных органах H. lancifolia содержание аскорбиновой кислоты понижалось с весны до осени и было незначительное: в 2010 г. - с 8,4 до 6,6 мг\%, в 2011 г. с 7,8 до 5,5 мг\%, в 2012 г. - с 13,3 до 10,5 мг\%. Что касается пектинов и протопектинов, то содержание последних в 2-3 раза больше в подземных органах. Установлено, что пектинов было к осени наибольшее количество (2,54\%) в 2010 г. С весны 2011 г. их содержание оставалось таким же, а к июлю уменьшалось в 3 раза и к осени увеличивалось в 2 раза по сравнению с июлем (табл. 1). Однако в 2012 г. пектинов было в июле 2,08\%, т.е. в 3 раза больше, чем в мае, а в сентябре в 2 раза меньше. Содержание протопектинов в 2010-2012 гг. понижалось к осени в 1,5-2 раза по сравнению с весной. Содержание катехинов в подземных органах во все годы наблюдений изменялось от 0,03 до $0,10 \%$, только в теплый засушливый период 2012 г. в июле месяце оно было повышено в 10 раз. По сапонинам установлено, что в 2010-2011 гг. их содержание увеличивалось с мая по сентябрь в 1,5-3 раза. В 2012 г. наблюдали уменьшение количества сапонинов в подземных органах с мая по сентябрь в 4 раза (табл. 1).

Haдземные органы. Установлено, что содержание флавонолов в листьях H. lancifolia колебалось в зависимости от вегетационных периодов. Так, в 2010 г. оно в 7 раз увеличивалось в период массового цветения (июль). К концу вегетации (сентябрь) количество флавонолов уменьшилось (0,37\%). В 2011 г. наблюдали постепенное увеличение содержания флавонолов в листьях H. lancifolia с 1,08 до 2,0\%. В мае 2012 г. их было 1,58\%, т.е. в 2 раза больше, чем в июле, к сентябрю их содержание составляло 1,23\% (рис. 2).

Расход и накопление содержания аскорбиновой кислоты в летний сезонный период в наземных органах также изменялось по годам. В теплый умеренно-увлажненный 2010 г. ее накопление в листьях было наибольшее в июле (50,8 мг\%). В слабозасушливый 2011 г. содержание аскорбиновой кислоты в листьях к осени увеличивалось в 2-3 раза по сравнению с весенне-летней вегетацией. Однако в засушливый 2012 г. наблюдали понижение содержания аскорбиновой кислоты с весны до осени в 2-4 раза. 


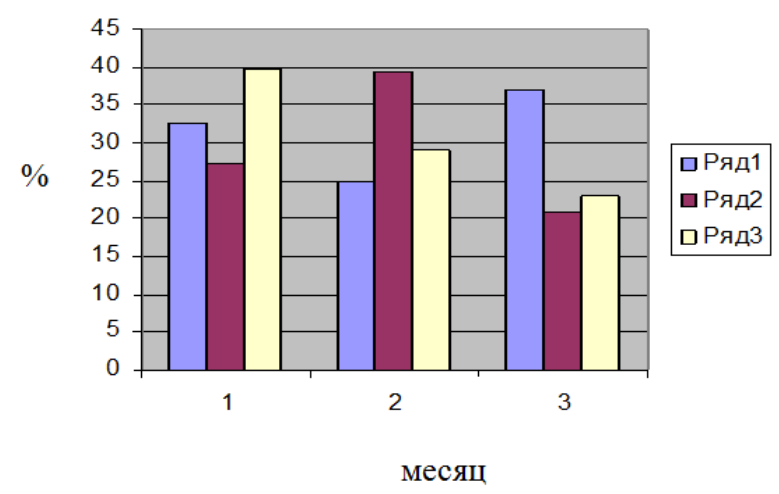

Рис. 1. Содержание крахмала в подземных органах Hosta lancifolia: 1 - 2010 г., 2 - 2011 г., 3-2012 г., ряд 1 - май, ряд 2 - июль, ряд 3 - сентябрь

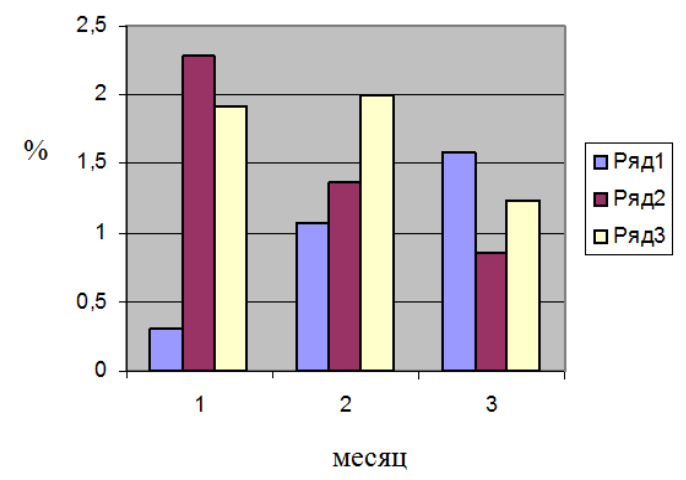

Рис. 2. Содержание флавонолов в надземных органах Hosta lancifolia: 1 - 2010 г., 2 - 2011 г., 3 - 2012 г., ряд 1 - май, ряд 2 - июль, ряд 3 сентябрь

Установлено, что в период вегетации и цветения накопление пектинов в надземных органах было незначительным во все годы наблюдений. Причем в 2010 г. содержание пектинов понижалось с мая по сентябрь в 3 раза, в 2011 г. их динамика была относительно стабильна (0,98-1,45\%). В 2012 г. наибольшее содержание пектинов, как и аскорбиновой кислоты, наблюдали в листьях в мае в период интенсивного отрастания и вегетации. К сентябрю их количество в листьях уменьшалось в 4 раза (табл. 2). Содержание протопектинов во все годы наблюдений было в листьях в 1,5-10 раз больше, чем пектинов, и составляло 4,29-7,67\% в течение сезонного развития. Накопление катехинов в листьях H. lancifolia было максимальное в период массового цветения в июле 2010 и 2012 гг. и составляло 0,69 и 0,41\% соответственно. Относительно количественного соотношения сапонинов нами установлена изменчивость этого показателя по годам. Причем во все годы наблюдения их содержание было относительно стабильное $(12,40-13,82 \%)$ в период весеннего отрастания. Высокое содержание сырого сапонина (22,92 и 25,71\%) у H. lancifolia установлено во время плодоношения в сентябре.

Выявлено, что содержание сахара в 2010 г. повышалось незначительно в листьях к предзимью с 18,62 до 20,98\%. В 2011 г. оно было стабильное, но в 1,5-2,5 раза меньше по сравнению с 2010 г. Установлено, что в 2012 г. динамика его накопления и расхода характерна показателям 2010 г., причем понижение содержания сахара наблюдали с мая по июль месяцы в 4 раза и повышение его количества в 3 раза к сентябрю по сравнению с июлем (табл. 2) в слабозасушливый 2011 г. и засушливый 2012 г, тогда как в умеренно-увлажненный вегетационный период 2010 г. содержание сахаров в листьях к осени было в 8 9 раз меньше.

\section{Обсуждение результатов}

Таким образом, в условиях Новосибирска (Приобская лесостепная климатическая провинция) для H. lancifolia нами впервые установлено, что количественное содержание крахмала как полимера глюкозы в подземных органах изменяется к предзимью: в 2010 г. возрастает, в 2011-2012 гг. уменьшается в 1,5-2 раза, тогда как содержание сахара, наоборот, в 2010 г. уменьшается к осени, в 2011 г. увеличивается в 2 раза, в 2012 г. - стабильное. Накопление сахара в корневищах перед зимним покоем обеспечивает устойчивость почек возобновления, где формируются генеративные побеги. Увеличение содержания крахмала как нерастворимого полисахарида способствует ускорению метаболических процессов в запасающих тканях корневищ, что в целом обусловливает их значительную морозоустойчивость и усиливает адаптационные возможности H. lancifolia в период зимнего покоя в Сибири.

Известно, что тритерпеновые сапонины служат факторами невосприимчивости растений к грибковым заболеваниям [14]. В засушливые и слабозасушливые вегетационные периоды их концентрация в вегетативных органах повышается, особенно в наиболее жаркий месяц - июль. Наличие сапонинов, аскорбиновой кислоты и катехинов в составе перезимовавших корневищ способствует устойчивости этого вида к факторам среды, к микрофлоре в период ежегодного весенне-летне-осеннего роста и развития. Индивидуальная изменчивость распределения и накопления метаболитов в листьях и корневищах проявлялась как 
в период сезонного развития, так и в зависимости от агроклиматических условий вегетационных периодов 2010-2012 гг.. Так, в более засушливый вегетационный период 2012 г. содержание сахара, аскорбиновой кислоты, катехинов в подземных органах было стабильным по сравнению с умеренно-увлажненным и слабозасушливыми периодами 2010-2011 гг. Одновременно в 2012 г. к осени отмечено снижение содержания пектинов, протопектинов, крахмала в корневищах, а в листьях - аскорбиновой кислоты и пектинов. С повышением возраста в листьях H. lancifolia увеличивалось содержание протопектинов и пектинов. Последние регулируют водоудерживающую способность растений, тем самым оберегая их от солнечных ожогов. Изменение динамики запасных и биологически активных веществ в надземных и подземных органах H. lancifolia обусловлено рядом особенностей, в том числе возрастным состоянием интродуцируемых растений, их сезонным развитием и метеорологическими факторами, что способствует жизнеустойчивости данного вида при интродукции в экстремальных условиях Сибири.

\section{Bыводbl}

1. Установлены индивидуальные и общие закономерности накопления и расхода запасных и биологически активных веществ в листьях и корневищах H. lancifolia. Определено шесть общих групп соединений: сахаров, аскорбиновой кислоты, пектинов, протопектинов, катехинов, сапонинов.

2. В подземных и надземных органах H. lancifolia в 2-7 раз больше протопектинов, чем пектинов в течение трех периодов вегетации. Содержание аскорбиновой кислоты в надземных органах H. lancifolia выше в 3-7 раз, чем в подземных; сахаров - в 2-10, катехинов - в 1,2-2 раза соответственно. Количество сырого сапонина в вегетативных органах H. lancifolia увеличивается к предзимью в 8-9 раз.

3. Количественное содержание крахмала и сахара обусловливает устойчивость подземных органов H. lancifolia в период зимнего покоя корневищ.

\section{Список литературы}

1. Hylander N. The genus Hosta in Swedish gardens // Acta Horti Berg. 1954. Vol. 16, N11. Pp. 55-58.

2. Полетико О.М. Род Ноsta Tratt. - Хоста //Декоративные травянистые растения. Л., 1977. Т. 2. С. 102-110.

3. Skrzypczakova L. Flavonoidy w rodzine Liliaceae // Dissert. Pharm. Pharmac. 1967. Vol XIX, N5. P. 537.

4. Bate-Smith E.C. The phenolic constituents of plants and their taxonomic significansce // J. Linn. Soc. (Bot.). 1968. Vol. 60. N383. P. 325.

5. Клышев Л.К., Бандюкова В.А., Алюкина Л.С. Флавоноиды растений. Алма-Ата, 1978. 219 с.

6. Седельникова Л.Л. Виды рода Hosta (Hostaceae) при интродукции в Западной Сибири // Вестник КГАУ, 2012. №11. С. 73-78.

7. Методы биохимического исследования растений / под ред. А.И. Ермакова. Л., 1987. 430 с.

8. Кукушкина Т.А., Зыков А.А., Обухова Л.А. Манжетка обыкновенная (Alchemilla vulgaris L.) как источник лекарственных средств // Актуальные проблемы создания новых лекарственных препаратов природного происхождения : материалы VII Международного съезда. СПб., 2003. С. 64-69.

9. Беликов В.В., Шрайдер М.С. Методы анализа флавоноидных соединений // Фармация, 1970. №1. С. 66-72.

10. Бородова В.Я., Горенков Э.С., Клюева О.А., Малофеева Л.Н., Мегердичев Е.Я. Методические указания по химико-технологическому сортоиспытанию овощных, плодовых и ягодных культур для консервной промышленности. М., 1993. С. 64-65.

11. Государственная фармакопея. М., 1968. 816 с.

12. Химический анализ лекарственных растений / под ред. М.И. Гринкевич. М., 1983. С. 41-56.

13. Киселева А.В., Волхонская Т.А., Киселев В.Е. Биологически активные вещества лекарственных растений Южной Сибири. Новосибирск, 1991. 135 с.

14. Анисимов М.М., Чирва В.Я. О биологии тритерпеновых гликозидов // Успехи современной биологии, 1980. Т. 90 , вып. 3 (6). С. 351-364.

Поступило в редакичию 21 января 2015 г. 
Sedelnikova L.L. *, Kukushkina T.A. BIOLOGICAL ACTIVE SUBSTANCE OF THE VEGETATIVE ORGANS HOSTA LANCIFOLIA ENGL. (HOSTACEAE)

Central Siberian Botanical Garden of the Russian Academy of Sciences, ul. Zolotodolinskaya, 101, Novosibirsk 630090 (Russia),e-mail: lusedelnikova@yandex.ru

A quantitative composition of storage and biological active substances in vegetabl organs Hosta lancifolia was defined. Dynamics of accumulation of sugars, starch, saponins, ascorbic acid, pectins, protopectins, catechins in zhizomes and of leafs the given species in the forest-steppe zone of West Siberia was established for several the periodes. It is established that the content of biologically active agents of vegetative bodies of $\mathrm{H}$. lancifolia depends on individual and seasonal development of a look. Is 3-7 times higher than ascorbic acid in elevated bodies, than underground; sugar at 2-10, catechins at 1,2-2, pectin at $2-5$, protopectin at 2 . The quantity of a crude saponin increases to autumn by $8-9$ times. The content of starch in underground bodies changes during seasonal development, but to autumn it increases on $20-40 \%$.

Keywords: sugar, starch, saponin, vitamin C, flavonolov, pectin, protopectin, catechin, leaft, zhizome, Hosta lancifolia, Western Siberia

\section{References}

1. Hylander N. Acta Horti Berg. 1954, vol. 16, no. 11, pp. 55-58.

2. Poletiko O.M. Dekorativnye travjanistye rastenija. Leningrad, 1977, vol. 2, pp. 102-110. (in Russ.).

3. Skrzypczakova L. Dissert. Pharm. Pharmac. 1967, vol XIX, no. 5, p. 537.

4. Bate-Smith E.C. J. Linn. Soc. (Bot.). 1968, vol. 60, no. 383, p. 325.

5. Klyshev L.K., Bandjukova V.A., Aljukina L.S. Flavonoidy rastenij. [Flavonoids are plant]. Alma-Ata, 1978,219 p. (in Russ.).

6. Sedel'nikova L.L. Vestnik KGAU, 2012, no. 11, pp. 73-78. (in Russ.).

7. Metody biohimicheskogo issledovanija rastenij. [Methods of biochemical research plant], ed. A.I. Ermakov. Leningrad, 1987, 430 p. (in Russ.).

8. Kukushkina T.A., Zykov A.A., Obuhova L.A. Aktual'nye problemy sozdanija novyh lekarstvennyh preparatov prirodnogo prois-hozhdenija : materialy VII Mezhdunarodnogo s'ezda. [Actual problems of creating new drugs of natural origin : Proceedings of the VII International Congress]. St. Petersburg, 2003, pp. 64-69. (in Russ.).

9. Belikov V.V., Shrajder M.S. Farmacija, 1970, no. 1, pp. 66-72. (in Russ.).

10. Borodova V.Ja., Gorenkov Je.S., Kljueva O.A., Malofeeva L.N., Megerdichev E.Ja. Metodicheskie ukazanija po himiko-tehnologicheskomu sortoispytaniju ovoshhnyh, plodovyh i jagodnyh kul'tur dlja konservnoj promysh-lennosti. [Guidelines for Chemical Technology Variety Testing of vegetable, fruit and berry cultour for the canning industry]. Moscow, 1993, pp. 64-65. (in Russ.).

11. Gosudarstvennaja farmakopeja. [State Pharmacopoeia]. Moscow, 1968, 816 p. (in Russ.).

12. Himicheskij analiz lekarstvennyh rastenij. [Chemical analysis of medicinal plants]. ed. M.I. Grinkevich. Moscow, 1983, pp. 41-56. (in Russ.).

13. Kiseleva A.V., Volhonskaja T.A., Kiselev V.E. Biologicheski aktivnye veshhestva lekarstvennyh rastenij Juzhnoj Sibiri. [Biologically active substances of medicinal plants in Southern Siberia]. Novosibirsk, 1991, 135 p. (in Russ.).

14. Anisimov M.M., Chirva V.Ja. Uspehi sovremennoj biologii, 1980, vol. 90, no. 3 (6), pp. 351-364. (in Russ.).

Received January 21, 2015

Revised June 15, 2015

\footnotetext{
* Corresponding author.
} 